INGARDENIANA III 


\title{
ANALECTA HUSSERLIANA
}

THE YEARBOOK OF PHENOMENOLOGICAL RESEARCH

VOLUME XXXIII

\begin{abstract}
Editor-in-Chief
ANNA-TERESA TYMIENIECKA

The World Institute for Advanced Phenomenological Research and Learning Belmont, Massachusetts
\end{abstract}

a sequel to:

Vol. IV : Ingardeniana I

Vol. XXX : Ingardeniana II

as well as to the following volumes in philosophy and literature:

Vol. XII : The Philosophical Reflection of Man in Literature

Vol. XVIII : The Existential Coordinates of the Human Condition: Poetic - Epic - Tragic

Vol. XIX : Poetics of the Elements in the Human Condition. Part 1: The Sea

Vol. XXIII : Poetics of the Elements in the Human Condition. Part 2: The Airy Elements

Vol. XXVIII : The Elemental Passions of the Soul 


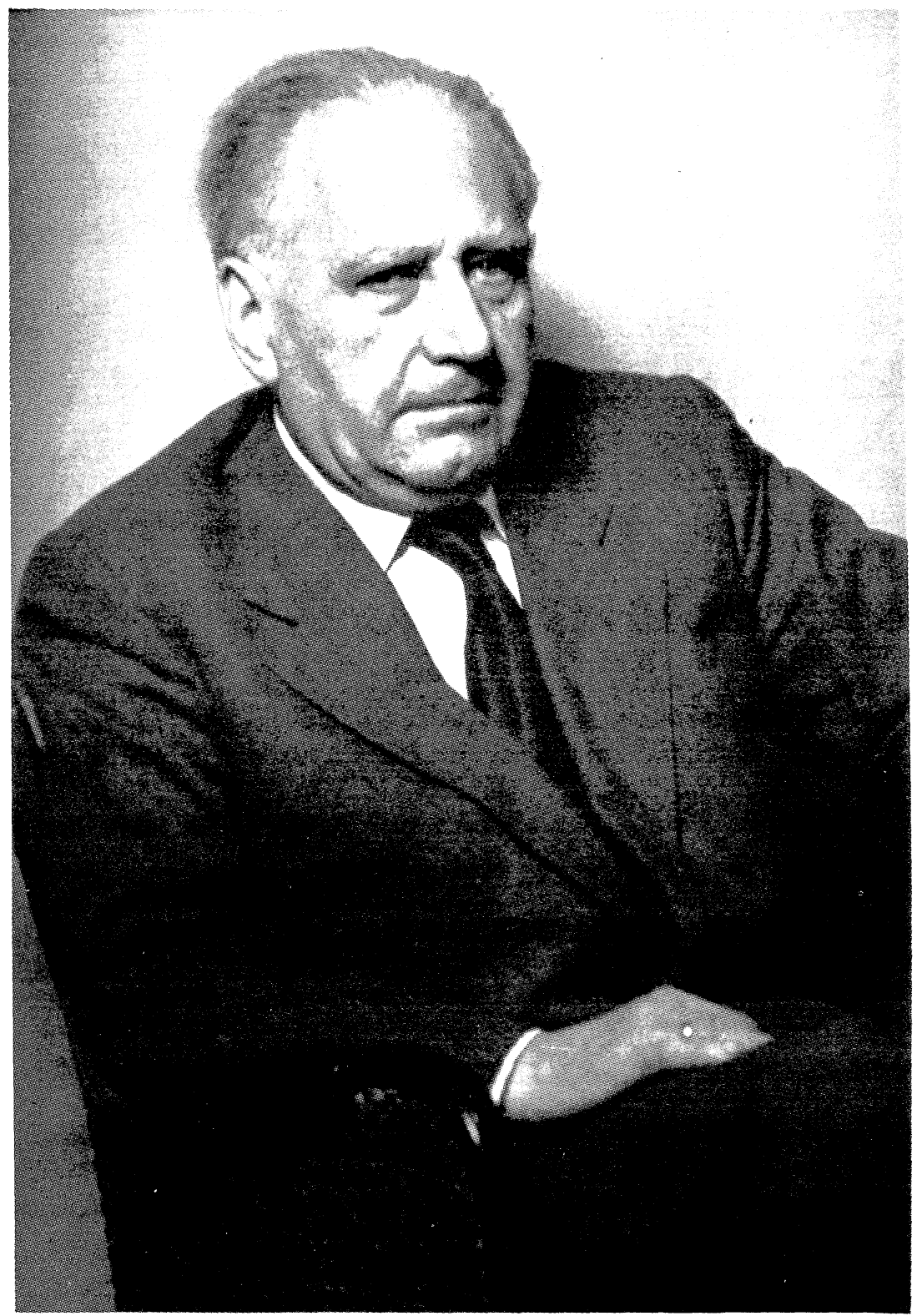

ROMAN INGARDEN (1893-1970)

Photo taken in 1958 and supplied by courtesy of Yushiro Takei. 


\title{
INGARDENIANA III
}

ROMAN INGARDEN'S AESTHETICS IN A

NEW KEY AND THE INDEPENDENT

APPROACHES OF OTHERS:

The Performing Arts, the Fine Arts, and Literature

\author{
Edited by \\ ANNA-TERESA TYMIENIECKA
}

The World Phenomenology Institute

Published under the auspices of

The World Institute for Advanced Phenomenological Research and Learning

A-T. Tymieniecka, President

SPRINGER-SCIENCE+BUSINESS MEDIA, B.V. 


\section{Library of Congress Cataloging-in-Publication Data}

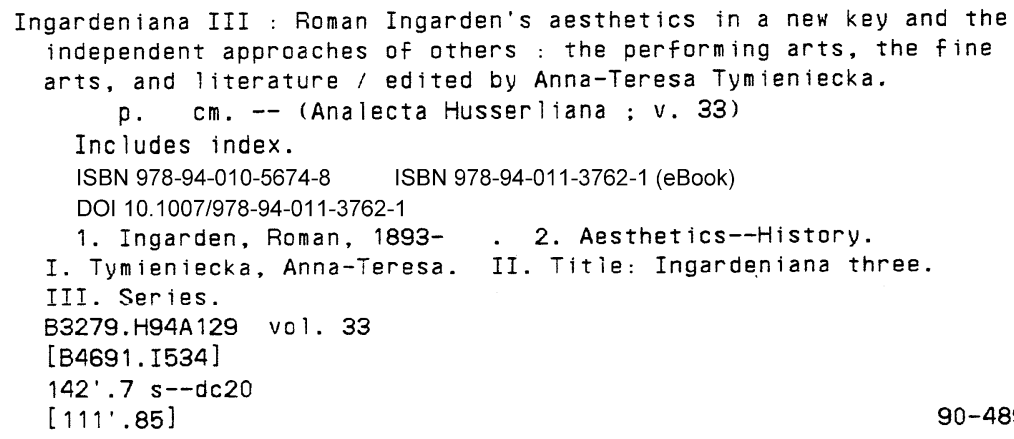

\section{Printed on acid-free paper}

All rights reserved.

(C)1991 Springer Science+Business Media Dordrecht

Originally published by Kluwer Academic Publishers in 1991

Softcover reprint of the hardcover 1st edition 1991

No part of the material protected by this copyright notice may be reproduced or utilized in any form or by any means, electronic or mechanical, including photocopying, recording or by any information storage and retrieval system, without written permission from the copyright owner. 


\section{TABLE OF CONTENTS}

Foreword

PART I

AESTHETICS OF THE PERFORMING ARTS:

DIFFERENT PHENOMENOLOGICAL PERSPECTIVES

JADWIGA S. SMITH / The Theory of Drama and Theatre: A

Continuing Investigation of the Aesthetics of Roman Ingarden

WACLAW M. OSADNIK and LUKASZ A. PLESNAR / On the

Sign Character of the Representing Stratum in a Film as

Work of Art

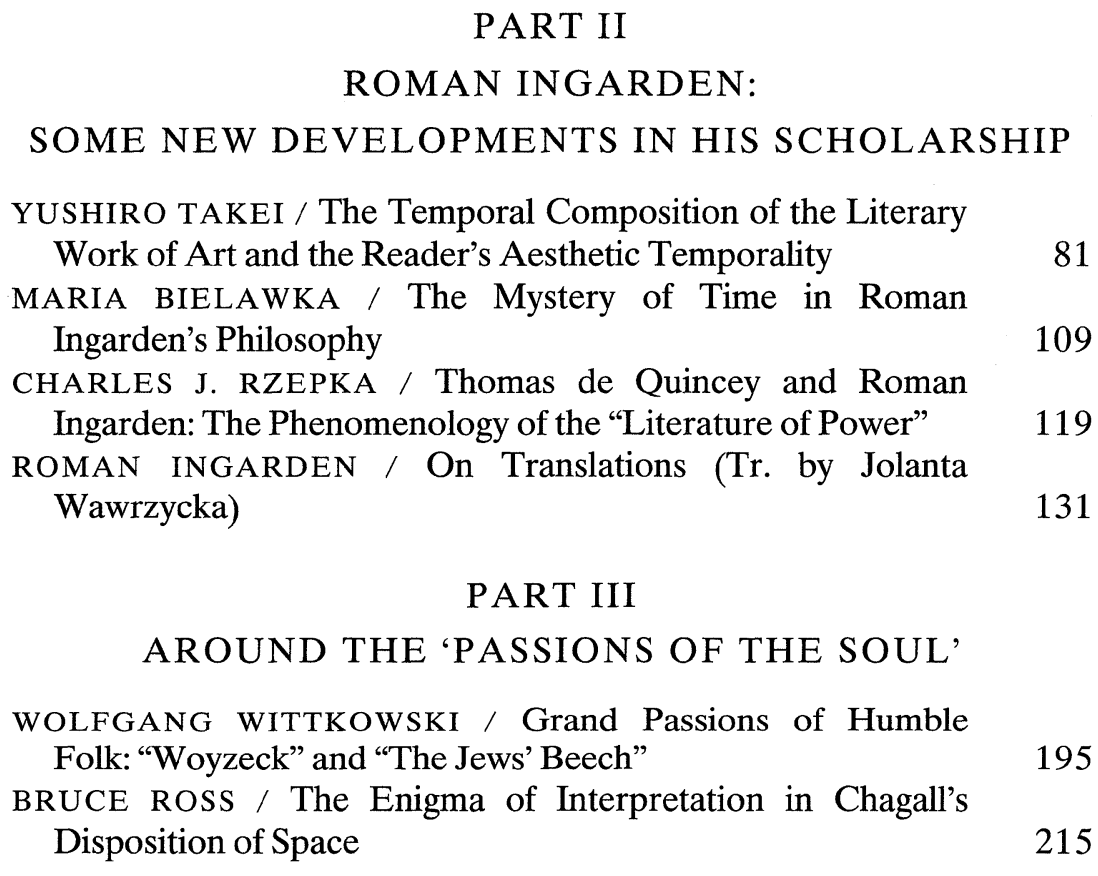


DANNY L. SMITH / Erotic Modes of Discourse: The Union of Mythos and Dialectic in Plato's Phaedrus

CONSTANTIN CRISAN / The Man of Genius as Artist Suffering and World Conscience

LEO RAUCH / The Erotic Phenomenology in Kierkegaard's Mozart

MARILYn STEWART / The Agamemnon: A Drama of the Passions

HANNA CHARNEY / Narrative Time as Interpretation of Human Existence: "Valence" in the Present of The Ambassadors

\section{PART IV}

\section{PHILOSOPHICAL VIEWS REFLECTED \\ IN LITERATURE}

MARIO SANCIPRIANO / Le langage de la création esthétique dans la phénomẻnologie

WILLIAM S. HANEY II / Unity in Vedic Aesthetics: The SelfInteracting Dynamics of the Knower, the Known, and the Process of Knowing

SUSUMU KANATA / An Approach to the Structure of the Japanese Elegy, in the Case of Yamanouë No Okura, a Representative Poet of Mannyoshu (The First Collection of Japanese Poetry)

RICHARD HULL / Fantastic Phenomenology

PETER MORGAN / Philosophic Filaments in Literature in English: Wordsworth to Pound

Index of Names 


\section{FOREWORD}

In the footsteps of Ingardeniana II, this volume marks the 20th anniversary of Roman Ingarden's death, partly focusing upon his thought, partly bringing his aesthetics into the present-day framework of research.

It might have appeared puzzling to the followers of our Analecta Husserliana why within the original horizon encircled by the research work of our International Society of Phenomenology and Literature whose research work is devised in a diametrically opposed direction to that of Roman Ingarden - there is steadfastly running through our discussions a line of Ingardenian reflection. The reason, as I have pointed out in the introduction to Ingardeniana II, expertly edited by Hans Rudnik, is clear: Ingarden's analysis of the intentional structures of works of art offers in its distinct and clear-cut forms an 'objective' correlate - as well as a point of reference - to the vast conundrum of issues concerning the creative endeavor of the writer, poet, artist in their struggle to endow life with its specifically human significance; a conundrum that in our research we are trying to disentangle elucidating its mysterious ramifications, their sources and dynamic virtualities.

As a matter of fact, Ingarden's thought, newly interpreted and originally expanded, occupies a legitimate place in the present collection. We find here, in the first place, an original expansion of Ingarden's aesthetic theory in the monograph of Jadwiga Smith followed by the essays of Wactaw Osadnik, Yushiro Takei and Charles Rzepka. Maria Bielawka's study of Ingarden's theory of time and the first English translation of his monograph on 'the art of translation' by Jolanta Wawrzycka complete the Ingarden focus.

The original and innovative nature of these studies deserves a special place in Ingardenian research.

Our attention is then brought to studies around the main subject of our own phenomenological 'poetics of the elements'. The focus upon the various aspects of the 'passions of the soul' is highlighted by the studies of Wolfgang Wittkowski, Constantin Crisan, Leo Rauch and others. 
Our focus expands in the fourth part of the book into various philosophical perspectives in literary and aesthetic theory comprising, after the leading study of Mario Sancipriano, different cross-cultural points of view: Western (Richard Hull, Peter Morgan), Vedic (William S. Haney II), Japanese (Susumu Kanata).

The study of Chagall's disposition of space' by Bruce Ross lies not only at the cross section of cultures (Judaic and Christian) but also blends the literary with the plastic art toward a full aesthetic enjoyment. 